\title{
Intracoronary Blood Flow Velocity and Transstenotic Pressure Drop in an Awake Human Being During Coronary Vasodilation
}

\author{
FELIX ZIJLSTRA, M.D., and PATRICK W. SERRUYS, M.D., Ph.D., FACC \\ From the Catheterization Laboratory, Thoraxcenter, Erasmus University, Rotterdam. The Netherlands
}

The pressure drop over a coronary stenosis and the intracoronary Doppler blood flow velocity were measured at rest and during coronary vasodilation. We report the first observation that confirms the validity of fluid dynamic equations to describe

\section{Introduction}

Recently, quantitative coronary arteriographic methods of calculating pressure-flow characteristics have been proposed to describe the hemodynamic consequences of a coronary stenosis. ${ }^{1-5}$ The fluid dynamic equations that are used in these methods have been validated in experimental animal preparations. ${ }^{1-3,6-8}$ This report describes the first observation that confirms the validity of these equations to describe the hemodynamic consequences of a coronary stenosis in an awake human being.

\section{Methods}

A 43-year-old man underwent cardiac catheterization for severe disabling angina despite intensive medical therapy. Coronary angiography showed single-vessel coronary artery disease with a lesion in the proximal left anterior descending artery. Left ventriculography showed an ejection fraction of $65 \%$ with normal systolic and diastolic wall motion. Subsequently, the patient underwent percutaneous balloon angioplasty. A guiding catheter was placed in the left main coronary artery

Address for reprints: Patrick W. Serruys, MD, Catheterization Laboratory, Thoraxcenter, Erasmus University, P.0. Box 1738, 3000 DR Rotterdam, The Netherlands.

Submitted for publication August 13, 1987; accepted January 4, 1988. the hemodynamics of a coronary stenosis based on quantitative arteriography in a human being. ( $\mathrm{J}$ Interven Cardiol 1988:1:1)

coronary stenosis, coronary vasodilation

and a long guidewire (length: $315 \mathrm{~cm}$, diameter: $0.14 \mathrm{in)}$ was passed through the coronary stenosis. Isosorbide dinitrate was given intracoronary several times during the procedure to ensure constant and maximal epicardial vasodilation.

\section{Intracoronary Blood Flow Velocity and Pressure Measurements}

A $20 \mathrm{MHz}$ pulsed Doppler probe mounted on the tip of the angioplasty catheter ${ }^{9}$ with a balloon diameter size of $3.4 \mathrm{~mm}$ was introduced over the guidewire. Recently, Sibley et al. validated clinically and experimentally the ability of a similar catheter with an end-mounted piezoelectric crystal to provide accurate continuous on-line measurement of coronary blood flow velocity and vasodilator reserve. ${ }^{10}$ The Doppler crystal has a $1.0-\mathrm{mm}$ diameter annulus with a $0.5-\mathrm{mm}$ central hole. Leads are soldered to each face and pushed through the catheter between the original $0.5-\mathrm{mm}$ lumen and a thin-walled tube that serves as a new $0.4-\mathrm{mm}$ lumen. The leads exit near the proximal Luer hub and are wired to a two-pin plug for connection to the pulsed Doppler instrument (Fig. 1). The mean and phasic spatially averaged blood flow velocities are measured continuously from the catheter tip transducer using a range-gated Doppler unit designed specially for this purpose. The sampling window was adjusted to obtain the 


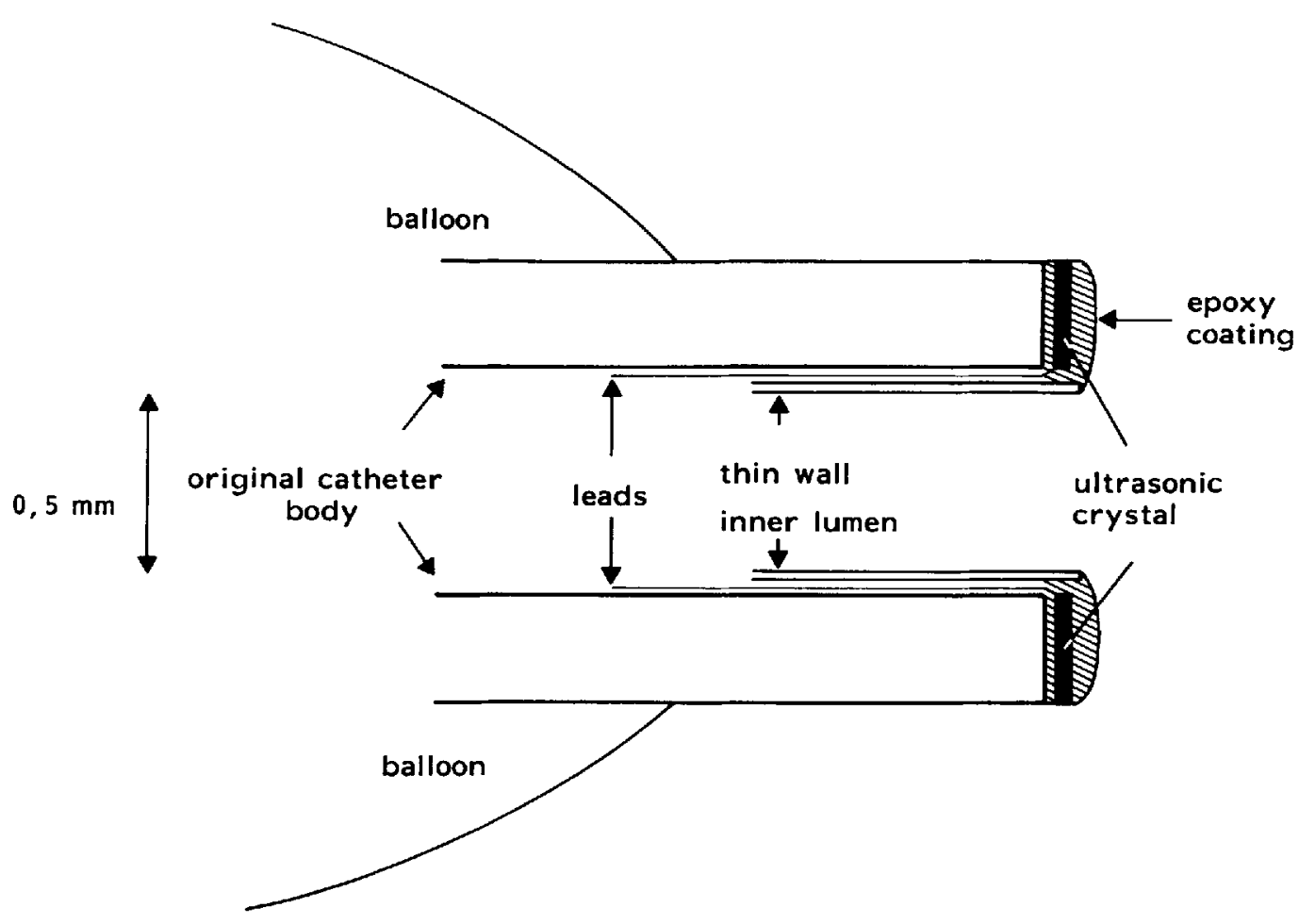

Figure 1. Schematic cross-sectional drawing of the Doppler-balloon catheter.

optimal signal that resulted in a sampling window of $1.8 \mathrm{~mm}$. The output of the pulsed Doppler is a frequency shift $(\Delta f)$ that can be related to blood velocity by the Doppler equation:

$$
\Delta \mathrm{f}=2 \mathrm{~F}(\mathrm{~V} / \mathrm{c}) \cos \mathrm{a},
$$

where $F$ is the ultrasonic frequency, $V$ is the velocity within the sampling volume, and a is the angle between the velocity vector and the sound beam. Using an end-mounted crystal with the catheter parallel $\left( \pm 2 \mathrm{O}^{\circ}\right)$ to the vessel axis, $\cos \mathrm{a}=1 \pm 6 \%$, and the relation between the Doppler shift and velocity is approximately $3.75 \mathrm{~cm} / \mathrm{s}$ per $\mathrm{KHz} .{ }^{9}$

Previous calibration experiments in canine femoral arteries have shown that the measured Doppler frequency shift is proportional to volume flow. ${ }^{10-13}$ After three balloon inflations with pressures up to 12 atmospheres and a total inflation time of 180 seconds the long guidewire was removed and the central lumen of the balloon catheter was vigorously flushed to record simultaneously the proximal intracoronary pressure through the guiding catheter, as well as the intracoronary pressure distal of the dilated lesion as previously described. ${ }^{14,15}$ In 13 selected heartbeats, blood flow velocity and proximal and distal intracoronary pressures were measured. For each heartbeat, velocity and pressures were measured in

Table 1. Pressure-flow Characteristics of Coronary Stenosis

\begin{tabular}{cccc}
\hline & & \multicolumn{2}{c}{ Pressure-drop (mmHg) } \\
\cline { 3 - 4 } $\begin{array}{c}\text { Flow Veloc } \\
\text { (cm/sec) }\end{array}$ & $\begin{array}{c}\text { Vol Flow } \\
(\mathrm{ml} / \mathrm{sec})\end{array}$ & x-Ray Predicted & Measured \\
\hline 12 & 1.0 & 14 & 11 \\
13 & 1.1 & 16 & 13 \\
14 & 1.2 & 17 & 17 \\
15 & 1.3 & 19 & 17 \\
16 & 1.3 & 21 & 17 \\
18 & 1.5 & 25 & 22 \\
19 & 1.6 & 28 & 28 \\
20 & 1.7 & 29 & 28 \\
21 & 1.8 & 31 & 28 \\
23 & 1.9 & 36 & 33 \\
24 & 2.0 & 38 & 32 \\
25 & 2.1 & 40 & 36 \\
26 & 2.2 & 43 & 36 \\
\hline
\end{tabular}

Flow veloc $=$ flow velocity measured with the intracoronary doppler catheter; vol flow $=$ calculated volume flow. 
early, mid, and late diastole, and these values were averaged to obtain a mean diastolic blood flow velocity and a mean diastolic pressure drop (Table 1). Resting intracoronary blood flow velocity and pressure drop over the residual stenosis were recorded. Thereafter, coronary vasodilation was induced by injecting $5 \mathrm{mg}$ papaverine subselectively through the distal lumen of the balloon catheter. ${ }^{16}$ The measured pressure drop increased from 11 to $37 \mathrm{mmHg}$ and the intracoronary blood flow velocity increased from 12 to $26 \mathrm{~cm} / \mathrm{s}$. During the subsidence of the hyperemic response following the papaverine injection, intracoronary pressures and blood velocity were recorded continuously. Two examples are shown in Figure 2.

\section{Quantitative Analysis of the Residual Coronary Artery Lesion}

After removal of the angioplasty catheter, coronary angiography of the dilated artery was performed in two orthogonal projections on $35-\mathrm{mm}$ cinefilm. There was no intimal dissection or haziness of the dilatation site. The determination of the coronary arterial dimensions have been implemented on the computer-based Cardiovascular Angiography Analysis System and have been described. ${ }^{5,17,18}$ The boundaries of the selected coronary artery segment were detected automatically from optically magnified and videodigitized regions of interest of a cineframe. Calibration of the
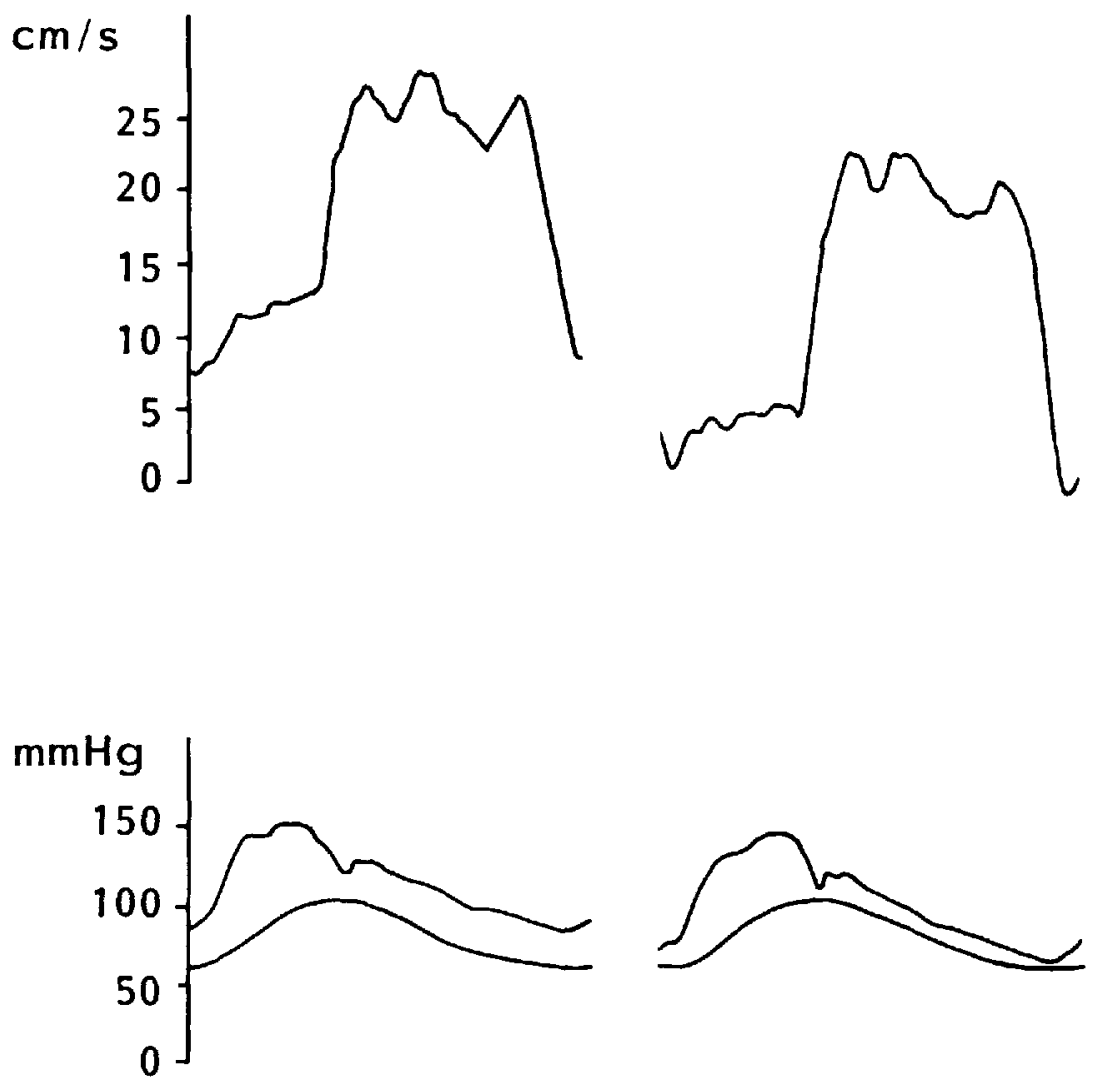

Figure 2. Two examples of the relationship between intracoronary blood flow velocity and intracoronary pressure proximal and distal to the stenosis. From top to bottom: intracoronary blood flow velocity $(\mathrm{cm} / \mathrm{s})$, proximal intracoronary blood pressure and distal intracoronary blood pressure $(\mathrm{mmHg}$ ). During papaverine induced hyperemia the increased intracoronary blood flow velocity is accompanied by an increased pressure drop across the stenosis (left heart beat), whereas after subsidence of the hyperemia (right heart beat) intracoronary blood flow velocity and pressure drop across the stenosis are considerably lower. 
diameter data in absolute values $(\mathrm{mm}$ ) was achieved by detecting the boundaries of a section of the contrast catheter and comparing the mean diameter in pixels with the known size in $\mathrm{mm}$. Each catheter is measured individually. ${ }^{19}$ The contour positions of the arterial and catheter segments were corrected for pincushion distortion. ${ }^{18}$ Since the functional significance of a stenosis is related to the expected normal area of the vessel at the point of obstruction, we used a computer estimation of the original arterial dimensions at the site of obstruction to define the reference region. ${ }^{18}$ The length of the obstructive lesion was determined from the diameter function on the basis of a curvature analysis. ${ }^{18}$ The percentage area stenosis and the minimal obstruction area $\left(\mathrm{mm}^{2}\right)$ were then calculated from the two orthogonal projections.

\section{Calculation of the Pressure Drop Flow Relation on the Basis of the Stenosis Geometry}

The theoretical pressure drop was calculated according to the fluid dynamic equations validated in experimental animal preparations:

$$
\Delta \mathrm{P}=\left[\frac{8 \pi \mu \mathrm{LA}_{\mathrm{n}}}{\mathrm{A}_{\mathrm{s}}^{2}}\right] \mathrm{V}+\frac{\rho}{0.266}\left[\frac{\mathrm{A}_{\mathrm{n}}}{\mathrm{A}_{\mathrm{s}}}-1\right]^{2} \mathrm{~V}^{2}
$$

where $\Delta P$ is pressure drop across the stenosis, $\mu$ is absolute blood viscosity, $L$ is stenosis length, $A_{s}$ is the minimal cross-sectional area of the stenosis, $A_{n}$ is cross-sectional area of the normal artery, $p$ is blood density, $\mathrm{V}$ is flow velocity through the normal portion of the artery.

For volume flow $(Q)$ this equation can be rewritten as:

$$
\Delta \mathrm{P}=\left[\frac{8 \pi \mu \mathrm{L}}{\mathrm{A}_{\mathrm{s}}^{2}}\right] \mathrm{Q}+\frac{\rho}{0.266}\left[\frac{1}{\mathrm{~A}_{\mathrm{s}}}-\frac{1}{\mathrm{~A}_{\mathrm{n}}}\right]^{2} \mathrm{Q}^{2}
$$

In a simplified form this equation can be described as:

$$
\Delta \mathrm{P}=\mathrm{fV}+\mathrm{sV}^{2}
$$

where $f$ is the coefficient of pressure loss due to viscous friction (Poiseuille resistance) and $s$ is the coefficient of pressure loss due to exit separation.

\section{Results}

The quantitative measurements of the coronary artery showed a percentage area stenosis of $72 \%$ and a percentage diameter stenosis of $51 \%$. For the calculation of the theoretical or $\mathrm{x}$-ray predicted pressure drop, the stenosis area was corrected for the cross-sectional area of the balloon catheter with the balloon deflated. The diameter of the angioplasty catheter was measured with a microcaliper. We calculated a stenosis area of $0.8 \mathrm{~mm}^{2}$. The measured flow velocity and pressure drop, as well as the calculated volume flow and pressure drop are shown in Table 1. Linear regression analysis of $\mathrm{x}$-ray predicted versus measured pressure drop showed: $x$-ray predicted pressure drop $=1.1$ $\times$ measured pressure drop $+1 \mathrm{mmHg}$, and an $r$ value of 0.98 (95\% confidence interval 0.94 to 0.99 ), with a SEE of $2 \mathrm{mmHg}$. The mean difference of the individual measurements between calculated and measured pressure drop was $11 \%$. Angiographic measurement of the luminal cross-sectional area in the postangioplasty state may be difficult due to microdissections. ${ }^{20,21}$ Measurement of the cross-sectional area of the deflated angioplasty catheter with a microcaliper could be erroneous to some extent. Therefore, we show the relationship between the measured intracoronary blood flow velocity, the theoretical or $\mathrm{x}$-ray predicted pressure drop, and the measured pressure drop in Figure 3 for stenosis areas ranging from 0.6 to $0.9 \mathrm{~mm}^{2}$.

\section{Discussion}

The visual assessment of coronary angiograms inadequately predicts the physiological significance of a coronary stenosis. ${ }^{22}$ Recently, two approaches have been developed to overcome this problem. First, regional vasodilatory reserve can now reliably be assessed with intracoronary blood flow velocity measurements or by radiographic measurements of myocardial perfusion using contrast media. ${ }^{5,13,23}$ Second, computer-based quantitative analysis of the coronary angiogram makes possible the calculation of hemodynamic parameters of the coronary artery lesion. ${ }^{3-5}$ Gould et al. validated the fluid dynamic equations that can be 


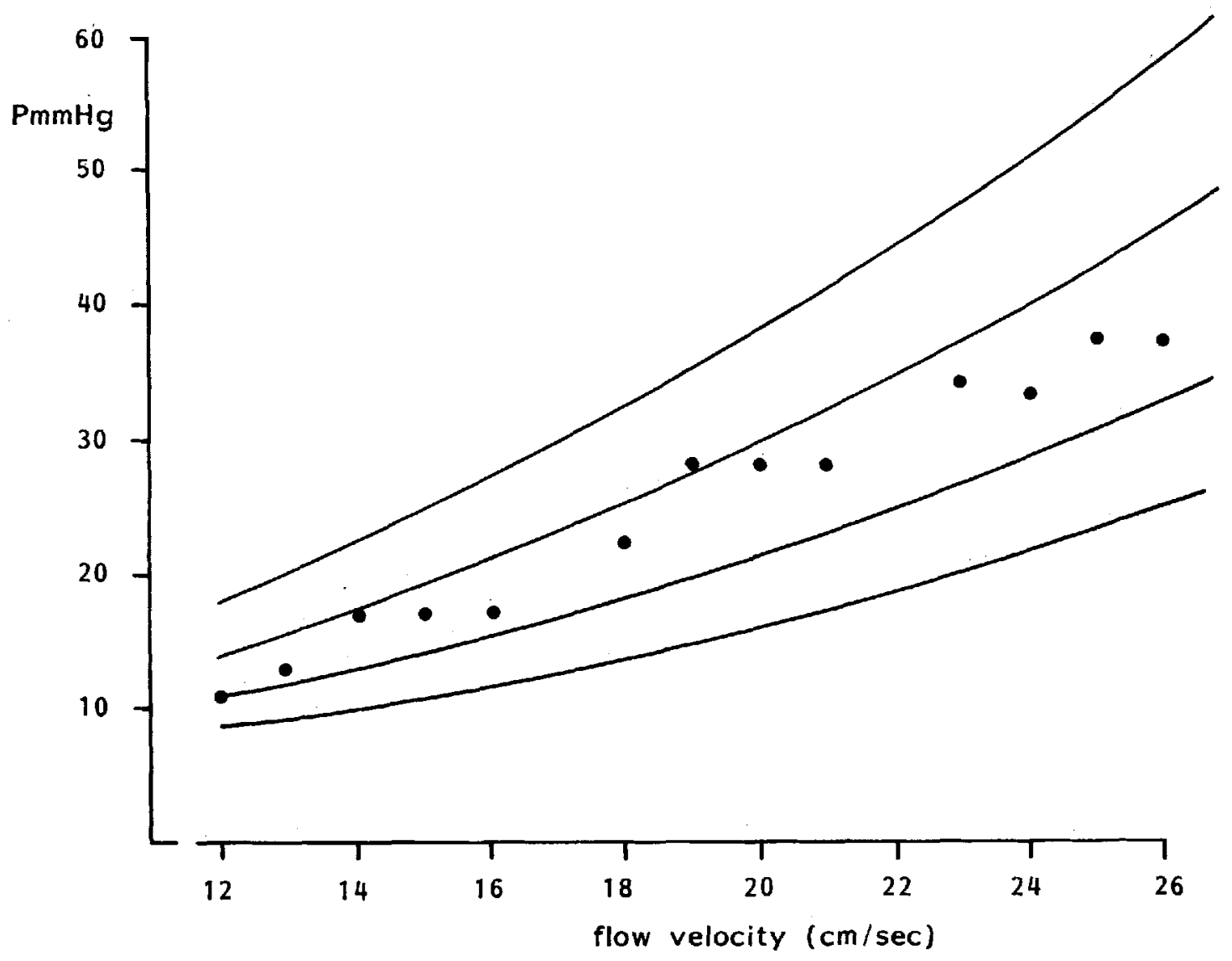

Figure 3. Relationship between the measured intracoronary blood flow velocity and the pressure drop $(P)$ across the stenosis. The measured pressure drop is represented by the dots. The calculated pressure flow characteristics are represented by the lines; from top to bottom, stenosis areas $0.6,0.7,0.8$, and $0.9 \mathrm{~mm}^{2}$.

used to determine pressure flow characteristics of a coronary stenosis on the basis of $\mathrm{x}$-ray determined geometry. ${ }^{3}$ In their study a considerable scatter of measured versus $\mathrm{x}$-ray predicted pressure drop was found despite an excellent overall correlation. The authors stated that this was mainly due to difficulties in visually tracing arterial borders on angiograms. We have used an extensively validated and highly accurate computer-assisted technique that includes automated contour detection. ${ }^{17,18}$ Nevertheless, small errors in measured cross-sectional area of the stenosis and/or the deflated angioplasty catheter could result in a downward or upward shift of the calculated pressure flow relationship. Therefore, we show the pressure flow characteristics of the stenosis for stenotic areas ranging from 0.6 to 0.9 in Figure 3. Regardless of the potential error in quantification of the stenotic area, the calculated and measured relationship between pressure and flow remains characterized by a similar curvilinear pattern. Previous work from our laboratory showed that hemodynamic parameters calculated from $\mathrm{x}$-ray geometry are correlated with measured coronary flow reserve, ${ }^{5}$ measured translesional pressure gradient, ${ }^{14}$ and exercise thallium perfusion scintigraphy. ${ }^{15}$ Therefore, the concept that quantitative analysis of coronary artery dimensions can be used to predict the physiological significance of a coronary stenosis is attractive.

This report is the first observation in an awake human being suggesting that this quantitative angiographic approach to determine the pressure flow characteristics of a coronary stenosis is applicable in the clinical setting. A new generation of 


\section{ZIJLSTRA, ET AL.}

Doppler tip angioplasty catheters has made this observation possible, but it needs to be further investigated and confirmed in a large series of patients.

\section{References}

1. Young DF, Cholvin NR, Roth AC. Pressure-drop across artificially induced stenoses in the femoral arteries of dogs. Circ Res 1975; 36:735-743.

2. Young DF, Cholvin NR, Kirkeeide RL, et al. Hemodynamics of arterial stenoses at elevated flow rates. Circ Res 1977; 41:99-107.

3. Gould KL, Kelley KO, Bolson EL. Experimental validation of quantitative coronary arteriography for determining pressure flow characteristics of coronary stenosis. Circulation $1982 ; 66: 930-937$.

4. Kirkeeide RL, Gould KL, Parsel L. Assessment of coronary stenoses by myocardial perfusion imaging during pharmacologic coronary vasodilation. VII Validation of coronary flow reserve as a single integrated functional measure of stenosis severity reflecting all its geometric dimensions. J Am Coll Cardiol 1986; 7:103-113.

5. Zijlstra F, van Ommeren J, Reiber JHC, et al. Does quantitative assessment of coronary artery dimensions predict the physiological significance of a coronary stenosis. Circulation 1987; 75:1154-1161.

6. Young DF, Tsai FY. Flow characteristics in models of arterial stenoses I. Steady flow. J Biomech 1973; 6:395410.

7. Young DF, Tsai FY. Flow Characteristics in models of arterial stenoses II. Unsteady flow. J Biomech 1973; 6:547-559.

8. Seeley BD, Toung DF. Effects of geometry on pressure losses across models of arterial stenoses. J Biomech 1976; 9:439-448

9. Serruys PW, Juillière $Y, Z$ Zijlstra $F$, et al. Coronary blood flow velocity during PTCA: a guide line for assessment of functional results. Am $\mathbf{J}$ Cardiol, In press.

10. Sibley DH, Millar HD, Hartley CJ, et al, Subselective measurement of coronary blood flow velocity using a steerable Doppler catheter. J Am Coll Cardiol 1986; 8:1332-1339.

11. Hartley CJ, Cole JS. An ultrasonic pulsed Doppler system for measuring blood flow in small vessels. J Appl Physiol 1974; 37:626-629.

12. Hartley CJ, Millar HD, Sibley DH, et al. Subselective coronary flow velocity measurement in man. IEEE cat. no. 1986: $\mathrm{CH} 2368,1023-1025$.

13. Wilson RF, Laughlin DE, Ackell $\mathrm{PH}$, et al. Transluminal subselective measurement of coronary artery blood flow velocity and vasodilator reserve in man. Circulation 1985; 72:82-92.

14. Serruys PW, Wijns $W$, Reiber JHC, et al. Values and limitations of transstenotic pressure gradients measured during percutaneous coronary angioplasty. Herz 1985; $6: 337-342$.

15. Wijns W, Serruys PW, Reiber JHC, et al. Quantitative angiography of the left anterior descending coronary artery: correlation with pressure gradient and results of thallium scintigraphy. Circulation 1985; 71:273-279.

16. Zijlstra F, Serruys PW, Hugenholtz PG. Papaverine: The ideal coronary vasodilator for investigating coronary flow reserve? A study of timing, magnitude, reproducibility and safety of the coronary hyperemic response after intracoronary papaverine. Cath Cardiovasc Diag 1986; 12:298-303.

17. Reiber JHC, Serruys PW, Kooijman $\mathrm{Cl}$, et al. Assessment of short-, medium-, and long-term variations in arterial dimensions from computer-assisted quantitation of coronary angiograms. Circulation $1985 ; 7: 280-288$.

18. Reiber JHC, Kooijman CJ, Slager CJ, et al. Coronary artery dimensions from cineangiograms; methodology and validation of a computer-assisted analysis procedure. IEEE Trans Med Imaging, 1984: Mİ-3:131-141.

19. Reiber JHC, Kooijman CJ, den Boer A, et al. Assessment of dimensions and image quality of coronary contrast catheters from cineangiograms. Cath Cardiovasc Diag 1985; 11:521-532.

20. Block PC, Myler RE, Stertzer S, et al. Morphology after transluminal angioplasty in human beings. $N$ Engl $J$ Med 1981; 305:382-385

21. Serruys PW, Reiber JHC, Wijns W, et al. Assessment of percutaneous transluminal coronary angioplasty by quantitative coronary angiography: diameter versus densitometric area measurements. Am J Cardiol 1984; $54: 482-488$.

22. White $C W$, Wright $C B$, Doty $D B$, et al. Does visual interpretation of the coronary arteriogram predict the physiologic importance of a coronary stenosis? $\mathrm{N}$ Engl J Med $1984 ; 310: 819-824$

23. Vogel RA. The radiographic assessment of coronary blood flow parameters. Circulation 1985; 72:460-465. 